\title{
A REVIEW OF GLACIER VARIATIONS IN THE TROPICS: THE PAST 500,000 YEARS
}

S. Hastenrath'

A review is presented of the field evidence for Pleistocene to early Holocene glaciations in the tropics. Recent glacier variations are described, and quantitative methods of climatic inference discussed.

Evidence of glaciations at $>100,000,300,000$ and 500,000 years B.P. at Kilimanjaro in East Africa is complemented by findings of a glaciation at $>100,000$ years B.P. in the Colombian Andes, of glaciations around 290,000 and 380,000 years B.P. in New Guinea, and around 135,000 and 250,000 years B.P. in Hawail. Furthermore the onset of deglaciation on the Ruwenzori in East Africa at $>14,700$ years B.P. agrees with the beginning of ice recession at $>14,000$ years B.P. in New Guinea, and is broadly consistent with evidence of glaciation in the South American Andes, namely at 28,000-14,000 years B.P.in Peru, at $<13,760$ years B.P. in Colombia, and at $>13,000$ years B.P. in Venezuela. On the Mexican volcanoes there are indications of glaciations at $34,000-32,000$, respectively at $>27,000$ and $>25,000$ years B.P., and of glacier advances during the interval 12,000-9,000 years B.P. Glaciations around 55,000 and 20,000 B.P. are reported at Hawaii. Beyond these absolute dates, spatial correlation of moraine complexes between Africa, the Americas, and Australasia is speculative. However, the onset of deglaciation is remarkably consistent throughout the tropics. For equatorial belt as whole, deglaciation progressed from around $3,000 \mathrm{~m}$ after about 15,000 years B.P. towards the $4,500 \mathrm{~m}$ level at 8,000 years B.P. The glacier variations appear to be paralleled, at least in part, by changes in vegetation and lakes.

At present, giaciers throughout the tropics continue a recession which began in the past century. The ice began to retreat after 1880 in East Africa, around the middle of the 19th century in New Guinea, and possibly even earlier in the Ecuadorian Andes. Modelling of the complete causality chain climate $\rightarrow$ net balance $\rightarrow$ ice dynamics $\rightarrow$ terminus variation permits a quantitative reconstruction of the unknown climatic forcing from the observed glacier response. A separate line of quantitative reconstruction of climate

\footnotetext{
${ }^{1}$ Department of Meteorology, University of Wisconsin, Madison-USA.
} 
history is based on the analysis of ice cores. Application of these techniques to the tropics in the past decade has led to remarkable success.

\section{REFERENCES}

HASTENRATH, S. (1984) The glaciers of equatorial East Africa. Dordrecht, D.Reidel Publ. 353p.

HASTENRATH, S. (1985) A review of Pleistocene to Holocene glacier variations in the tropics. Zeitschrift für Gletscherkunde und Glazialgeologie, 21:183-194.

HASTENRATH, S. (1988) Climate and circulation of the tropics. 2.ed. Dordrecht, D.Reidel Publ. 455p.

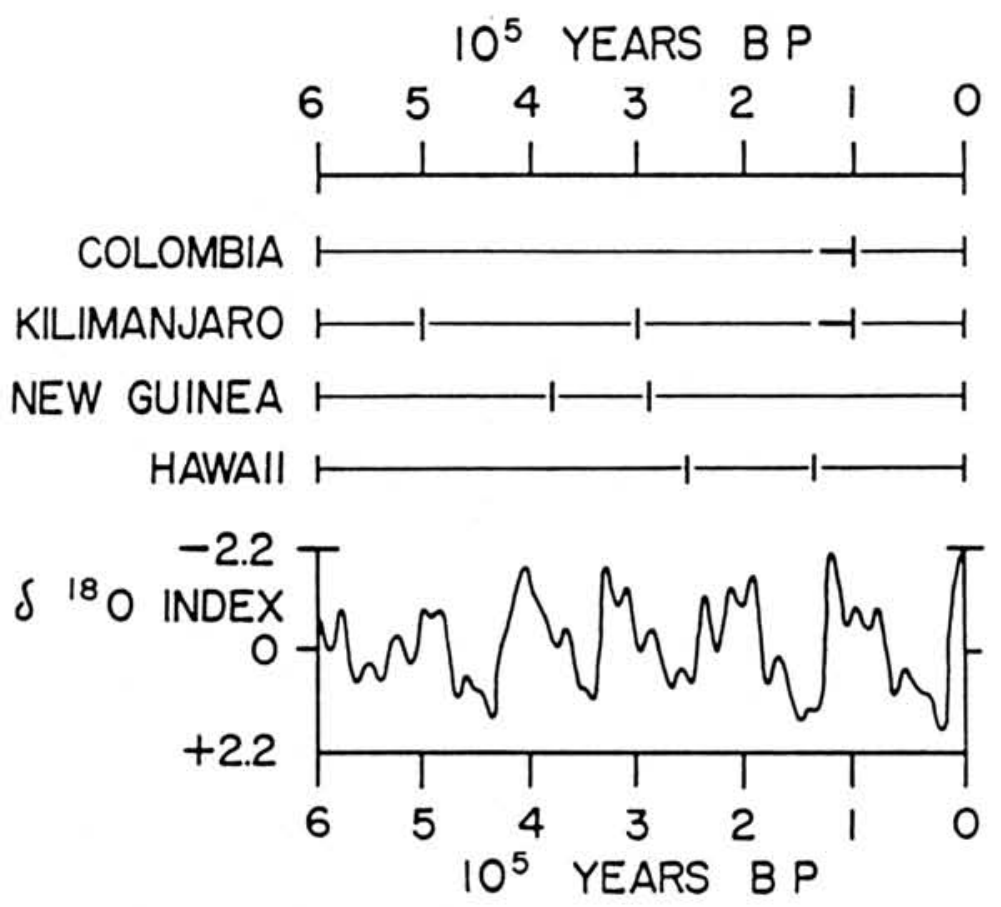

Figure 1- Comparison of older glaciations in Colombia, on Klimanjaro, in New Guinea, (top), and in Hawaii, with index of $\delta^{18} \mathrm{O}$ of sea water in the low-latitude ocean (bottom; deep-sea cases, variations normalized to zero mean and unit standard deviation). From HASTENRATH $(1984,1985)$. 


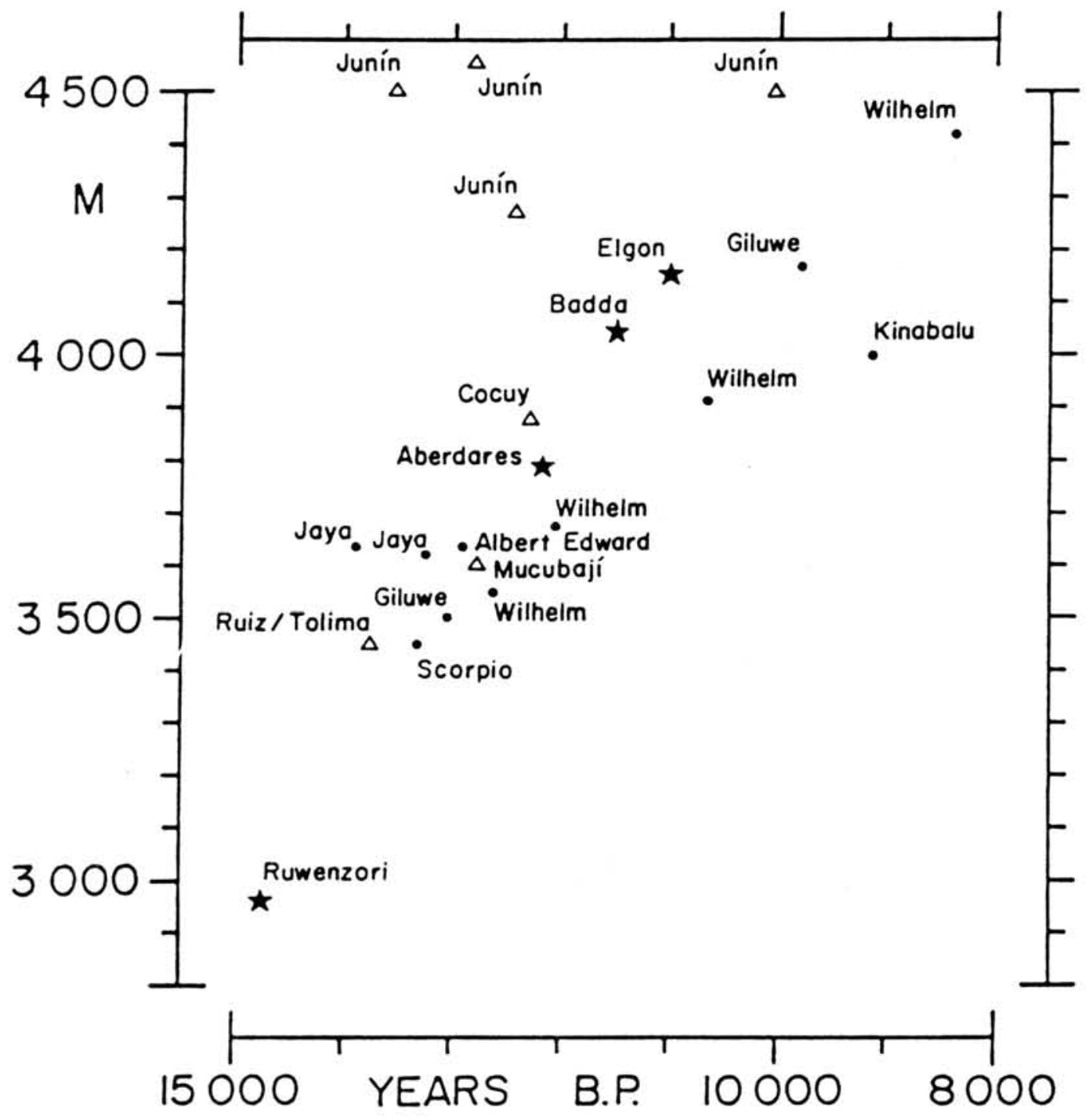

Figure 2- Variation of minimum deglaciation age with elevation. (a) Africa, stars, (b) Americas, triangles; (c) Australasia, dots. From HASTENRATH $(1984,1985)$. 